Ann. Biol. anim. Bioch. Biophys., Ig66, 6 (4), 503-5 I6.

\title{
CONTRIBUTION A L'ÉTUDE DU MÉTABOLISME DES LIPIDES CHEZ L'EMBRYON DE POULET : UTILISATION DES RÉSERVES VITELLINES EN PRÉSENCE D'ACIDE ÉLAÏDIQUE INCORPORÉ DANS L'EUF PAR LA POULE PONDEUSE
}

\author{
B. LECLERCQ \\ avec la collaboration technique de Michèle SAuveur \\ Station de Recherches avicoles, \\ Centre national de Recherches zootechniques, 78 -Jouy-en-Josas
}

\section{SOMMAIRE}

Deux lots de poules reçoivent l'un un régime témoin, l'autre un régime contenant de la triélaïdine. Dans les vitellus et les embryons nous isolons les triglycérides, les esters de cholestérol, les phosphatidyl-cholines et les phosphatidyl-éthanolamines; nous analysons leur composition en acides gras. Quel que soit le stade d'incubation, les triglycérides de l'embryon diffèrent peu de ceux de l'œuf. Les esters de cholestérol de l'embryon s'enrichissent en acide oléique entre le $10^{\circ}$ et le $2^{\mathrm{e}}$ jour. Les phospholipides de l'embryon se distinguent de ceux de l'œuf par de plus fortes teneurs en acide stéarique et en acide arachidonique. Les oufs des poules ingérant de la triélaïdine sont riches en acide élaïdique. Ils permettent le développement d'embryons normaux; de fortes proportions de l'isomère trans sont retrouvées dans leurs lipides. Les composés les plus riches par ordre décroissant sont : les esters de cholestérol, les triglycérides et les phospholipides. Une partie importante des acides gras de l'embryon semble provenir du vitellus.

Dans une étude bibliographique, CALET (I959) rappelle que la composition en acides gras des lipides de l'œuf dépend de la nature des matières grasses consommées par la poule. Nous avons montré antérieurement que l'ingestion de triélaïdine provoque l'incorporation dans l'œuf d'une quantité importante d'acide élaïdique ; elle conduit à des changements profonds de sa composition en acides gras (LECLERCQ, BLUm et JACQUOT, I965). Elle a pour conséquence une diminution des acides gras saturés, spécialement prononcée pour l'acide stéarique. L'acide oléïque, lui aussi, se retrouve en concentration plus faible, surtout dans les triglycérides. Comme chez le porc, (RAulin et al., Ig65) il semble que la synthèse d'acide arachidonique à partir d'acide linoléique soit notablement ralentie, ce qui entraîne une diminution de l'acide arachidonique et une accumulation de l'acide linoléïque non transformé. 
On sait (NEEDHAM, I93I) que les matières grasses de l'œuf d'oiseau servent à la fois aux besoins énergétiques et aux synthèses de l'embryon. Il nous est donc apparu intéressant de suivre l'utilisation des réserves vitellines modifiées par l'acide élaïdique, afin de savoir si l'embryon d'oiseau manifeste ou non une autonomie par rapport au régime maternel. En outre, certaines substances dépourvues pour l'adulte de toute toxicité apparente, peuvent être tératogènes. Nous nous sommes donc proposés d'étudier les effets physio-pathologiques éventuels des lipides hétérotypiques sur l'embryon de poulet.

\section{MATÉRIEI, ET MÉTHODES}

\section{I - Protocole expérimental}

Pendant une période préexpérimentale de 18 jours, 8 poules Rhode $\times$ Wyandotte reçoivent un régime de base $(\mathrm{RB})$ dont la composition est rapportée dans le tableau I ; ce régime est pauvre

\section{TABLEAU I}

Composition des régimes utilisés (en p. I00)

\begin{tabular}{|c|c|c|}
\hline & $\begin{array}{l}\text { Régime } \\
\text { de base }\end{array}$ & $\begin{array}{c}\text { Régime } \\
\text { expérimental }\end{array}$ \\
\hline Blé & 30,00 & 30,00 \\
\hline Tourteau de soja (extr.) ............ & 12,00 & 12,00 \\
\hline 'Tourteau d'arachide (extr.) .......... & 6,00 & 6,00 \\
\hline Levure $\ldots \ldots \ldots \ldots \ldots \ldots \ldots \ldots \ldots$ & 1,90 & 1,90 \\
\hline Lait écrémé $S_{p}$ ray ................ & 10,50 & 10,50 \\
\hline Farine de luzerne $\ldots \ldots \ldots \ldots \ldots \ldots \ldots$ & 3,00 & 3,00 \\
\hline Calcimarine $\ldots \ldots \ldots \ldots \ldots \ldots \ldots$ & 6,80 & 6,80 \\
\hline Phosphate bicalcique .............. & 3,00 & 8,00 \\
\hline Mélange vitaminique et minéral (1) . .... & 1,35 & 1,35 \\
\hline Sel vétérinaire $\ldots \ldots \ldots \ldots \ldots \ldots \ldots \ldots$ & 0,15 & 0,45 \\
\hline Cérélose $\ldots \ldots \ldots \ldots \ldots \ldots \ldots \ldots \ldots$ & 25,00 & 5,00 \\
\hline Triélaïdine $\ldots \ldots \ldots \ldots \ldots \ldots \ldots \ldots$ & 一 & 8,00 \\
\hline 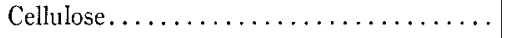 & - & 12,00 \\
\hline Analyse & & \\
\hline Matières grasses $(\mathbf{2})$ & 1,3 & 9,3 \\
\hline Protéines $\left({ }^{3}\right) \ldots \ldots \ldots \ldots \ldots \ldots \ldots$ & 15,6 & 15,6 \\
\hline Énergie métabolisable en $\mathrm{kcal} / \mathrm{kg}\left({ }^{3}\right) \ldots$ & 2710 & 2580 \\
\hline
\end{tabular}

(1)Mélange vitaminique et minéral pour $1000 \mathrm{~g}$ : vitamine A : $1000000 \mathrm{UI}$, vitanine $\mathrm{D}_{3}: 135000 \mathrm{UI}$, riboflavine : $0,3 \mathrm{~g}$, choline à 25 p. $100: 410 \mathrm{~g}$, pantothénate de calcium $: 0,7 \mathrm{~g}$, niacine $: 1,3 \mathrm{~g}, \alpha$-tocop hérol : $1000 \mathrm{UI}$, BHT : $7 \mathrm{~g}$, sulfate de manganèse $: 48 \mathrm{~g}$, DL-méthionine $: 80 \mathrm{~g}$, iodure de potassium : $0,1 \mathrm{~g}$, avoine broyée : ${ }^{1} 40 \mathrm{~g}$.

( $\left.{ }^{2}\right)$ Mesurées par la méthode de Kumagawa.

$\left({ }^{3}\right)$ Calculées d'après les données d'analyse des matières premières. 
en matières grasses. La nature et le taux des acides gras de ce régime sont indiqués dans le tableau 2. A la fin de cette période les animaux sont répartis en deux lots :

- lot Témoin : aliment non modifié.

- lot Élaïdique : aliment contenant 8 p. ıoo de triélaïdine. Ce régime dérive du régime de base : une partie du cérélose a été remplacée par un poids égal d'un mélange de cellulose et de triélaïdine pour que l'apport énergétique reste comparable.

\section{TABIEAU 2}

Composition en acides gras du régime de base

\begin{tabular}{c|c}
\hline Acides gras & P. 100 des acides gras \\
$14: 0$ & \\
$16: 0$ & 1,8 \\
$18: 0$ & 24,3 \\
$18: 1$ cis & 2,6 \\
$18: 2$ & 18,7 \\
$18: 3$ & 48,8 \\
& 3.5 \\
\end{tabular}

La composition en acides gras de la triélaïdine technique est rapportée dans le tableau 3 .

Après vingt jours d'expérience, le taux d'acide élaïdique de l'œuf pondu ne variant pas, les poules sont inséminées artificiellement tous les trois jours avec du sperme de coq Rhode Island Red.

\section{TABLEAU 3}

Composition en acides gras de la triélaïdine technique

\begin{tabular}{l|c}
\hline Acides gras & P. 100 des acides gras \\
$11^{\prime}: 0$ & 0,6 \\
$16: 0$ & 1,0 \\
$16: 1$ & 1,3 \\
$18: 0$ & 1,1 \\
$18: 1$ trans & 95,0 \\
$18: 1$ cis & traces \\
$18: 2$ & traces \\
&
\end{tabular}

Les ceufs sont conservés au plus trois jours à $12^{\circ} \mathrm{C}$ et à une hygrométrie de $65 \mathrm{p}$. Ioo. Ils sont placés dans un incubateur à air pulsé, à la température de $38^{\circ} \mathrm{C}$ et à une hygrométrie de $60 \mathrm{p}$. roo. Les embryons sont prélevés au bout de ro, i 4 et 20 jours d'incubation, débarrassés de leurs enveloppes et du vitellus restant. Les deux parties sont conservées pour l'analyse de leurs lipides.

\section{II - Méthodes d'analyse}

L'extraction des matières grasses est effectuée à froid par le mélange chloroforme-méthanoleau $(2-2-\mathrm{I}, \mathrm{V} / \mathrm{V} / \mathrm{V})$; les embryons sont broyés dans un homogénéiseur Virtis dans le mélange d'extraction. L'opération est répétée une seconde fois afin d'assurer une extraction maximum. 
Les graisses neutres sont ensuite séparées des phospholipides sur colonne d'acide silicique Puis on isole les différentes classes de graisses neutres sur plaques préparatives de Silica-Gel G (éluant : 85 éther de pétrole, I 5 éther éthylique, I acide acétique ; révélateur : Rhodamine $6 \mathrm{G}$ à I p. Ioo, dans le méthanol). On recueille la bande des triglycérides et celle des esters de cholestérol que l'on élue du gel par l'éther éthylique sur verre fritté.

Les différents phospholipides sont isolés sur plaques préparatives de silica gel HR selon la méthode de Skipski et Peterson ( 1963 ) et révélés par le réactif de DitTmer et Laster. On a ajouté à l'éluant de l'hydroquinone (Io mg/ Ioo cc) pour éviter l'oxydation des acides gras désaturés (NEUDOERFFER et LEA, 1966). Les bandes correspondant aux phosphatidyl-cholines et aux phosphatidyl-éthanolamines sont soigneusement grattées et recueillies. Les phospholipides correspondants sont élués par le méthanol sur verre fritté.

Les esters méthyliques des acides gras sont séparés et dosés par chromatographie gaz-liquide (colonne de 3 mètres et de $\mathrm{I} / 4$ pouce en acier inoxydable recuit, remplie de Chromosorb W 80/100 imprégné de $20 \mathrm{p}$. 100 de DEGS). L'acide élaïdique est dosé selon une micro-méthode précédemment décrite (LeclercQ, Agot et Lemarchal, ig66).

\section{RÉSULTATS}

\section{I - Résultats d'incubation}

Ils sont rassemblés dans le tableau 4 .

TABLEAU 4

Résultats d'incubation

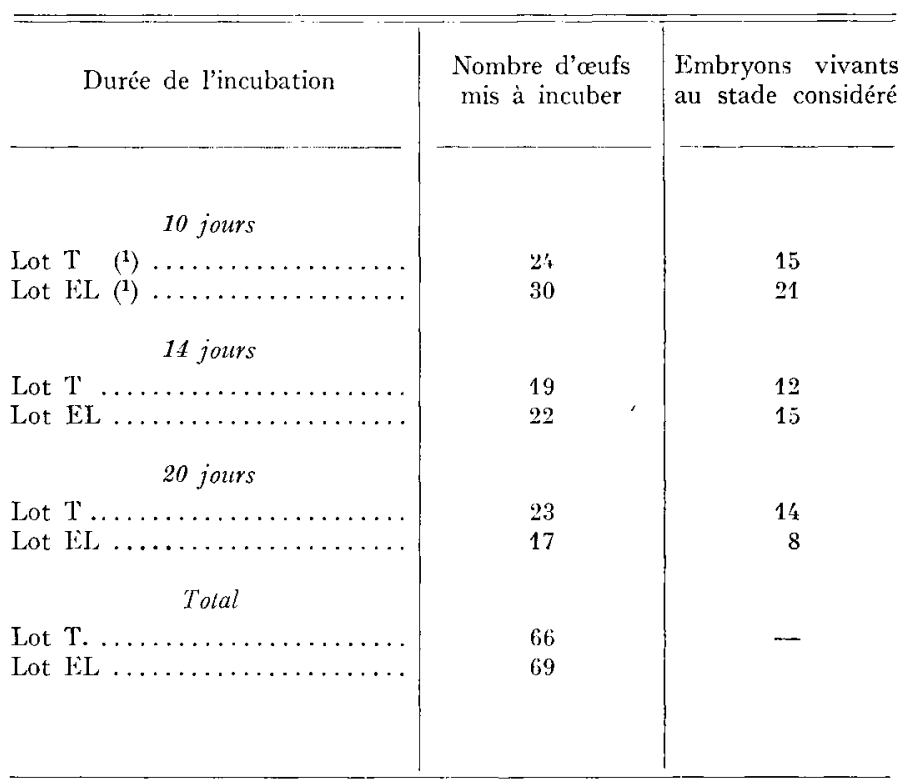

(1) Lot ' ' ' = lot témoin.

Lot $\mathrm{EL}=$ lot élaïdique. 
Dans le lot élaïdique nous avons éliminé un animal dont il a été impossible d'obtenir un œuf fertile, aussi bien au cours de l'expérience que de la préexpérience. Én tenant compte du petit nombre d'œufs mis à incuber, on ne trouve pas de différence significative entre les lots.

\section{2 - Poids et lipides totaux des embryons}

Ces résultats figurent au tableau 5. Il existe des variations entre individus, surtout lorsqu'ils proviennent de mères différentes. Malgré cette variabilité les résultats moyens obtenus dans les deux lots sont voisins.

TABLEAU 5

Poids, contenu lipidique et caractéristiques de l'embryon (moyenne)

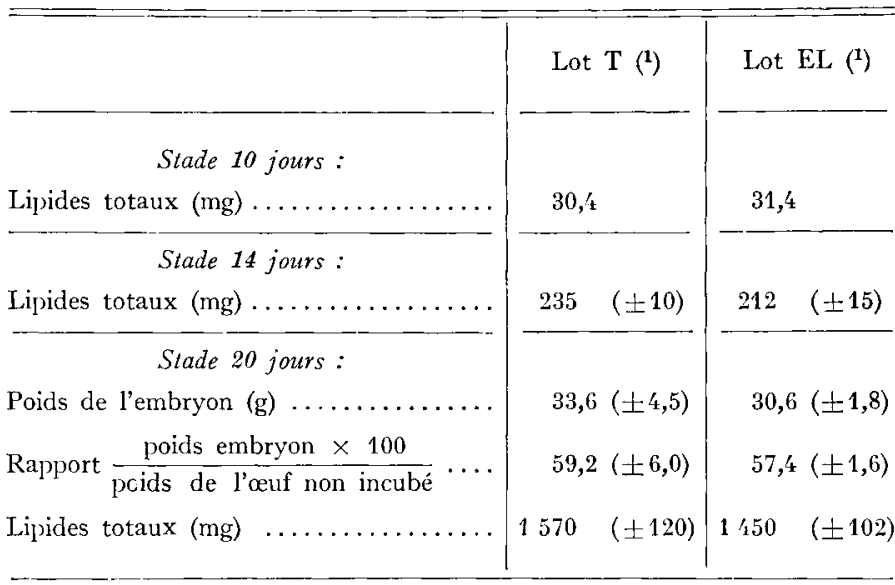

(1) Lot $\mathrm{T}=$ lot témoin Lot $\mathrm{EL}=$ lot élaïdique.

Les chiffres entre parenthèses correspondent aux écarts-types de la moyenne.

3 - Composition en acides gras du vitellus de l'xu' non incubé et $d u$ contenu du sac vitellin après incubation

Dans les graisses neutres nous n'analysons que les triglycérides et les esters du cholestérol. Dans le vitellus ces derniers ne sont pas recueillis parce qu'ils n'existent qu'à l'état de traces. Parmi les différentes classes de phospholipides nous n'avons analysé que les phophatidyl-cholines et les phosphatidyl-éthanolamines. Ces deux composants représentent plus de $90 \mathrm{p}$. Ioo des phospholipides du vitellus et au moins $70 \mathrm{p}$. roo de ceux de l'embryon. 8 et 9 .

La composition en acides gras de ces composés apparaît dans les tableaux 6,7 ,

On ne constate aucune modification importante dans la répartition des acides gras des constituants majeurs du vitellus au cours de l'incubation. 


\section{4 - Composition en acides gras des principaux lipides de l'embryon}

Dans les tableaux $6,7,8$, 9 et ro nous rapportons la composition en acides gras des triglycérides, des esters du cholestérol, des phospholipides totaux, des phosphatidyl-cholines et des phosphatidyl-éthanolamines des embryons aux stades IO, I4 et 20 jours.

\section{TABLEAU 6}

Composition en acides gras des triglycérides du vitellus et de l'embryon $\dot{a}$ divers stades d'incubation

\begin{tabular}{|c|c|c|c|c|c|c|c|c|c|}
\hline Acides gras $\left({ }^{1}\right)$ & $14: 0$ & $16: 0$ & $\begin{array}{c}16: 1 \\
\text { cis }\end{array}$ & $18: 0$ & $\begin{array}{c}18: 1 \\
\text { cis }\end{array}$ & $\begin{array}{l}18: 1 \\
\text { trans }\end{array}$ & $\left|\begin{array}{c}18: 2 \\
\text { cis-trans }\end{array}\right|$ & $\begin{array}{l}18: 2 \\
c i s-c i s\end{array}$ & $18: 3$ \\
\hline Vitellus non incubé & & & & & & & & & \\
\hline Lot $\mathrm{T}$ & 0,7 & 28,6 & 8,3 & 8,0 & 49,9 & 0,0 & 0,0 & 5,2 & traces \\
\hline Lot $\mathrm{E} 1 \ldots$ & 0,7 & 19,3 & 7,7 & 1,8 & 26,6 & 30,1 & 3,2 & 8,9 & 0,9 \\
\hline Vitellus résiduel & & & & & & & & & \\
\hline Lot $\mathrm{T}$ & 0,7 & 29,5 & 7,5 & 7,9 & 49,6 & 0,0 & 0,0 & 4,8 & traces \\
\hline Lot $\mathrm{E} 1 \ldots \ldots \ldots \ldots$ & 0,6 & 19,1 & 7,1 & 1,8 & 28,4 & 29,8 & 2,9 & 9,1 & 1,0 \\
\hline Embryon de 10 jours & & & & & & & & & \\
\hline Lot $\mathrm{T}$ & 1,0 & 32,2 & 5,7 & 9,7 & 46,2 & 0,0 & 0,0 & 5,2 & traces \\
\hline Lot El ... & 1,1 & 26,8 & 7,1 & 2,7 & 26,1 & 24,9 & 3,1 & 7,9 & traces \\
\hline Embryon de 1/t jours & & & & & & & & & \\
\hline Lot $\mathrm{T}$ & 0,9 & 31,9 & 6,0 & 7,3 & 45,4 & 0,0 & 0,0 & 7,0 & traces \\
\hline Lot El & 1,0 & 23,2 & 8,5 & 2,2 & 29,2 & 22,1 & 2,9 & 8,9 & traces \\
\hline Embryon de 20 jours & & & & & & & & & \\
\hline Lot $\mathrm{T}$ & 0,9 & 31,1 & 6,1 & 7,6 & 49,0 & 0,0 & 0,0 & 4,7 & traces \\
\hline Lot lil & 0,8 & 23,5 & 6,9 & 3,1 & 30,8 & 22,0 & 2,6 & 9,2 & traces \\
\hline
\end{tabular}

(1) Nous n'avons pas fait figurer ici des traces d'acides gras à nombre impair de carbones.

Les triglycérides, quoique très différents selon les lots, ne subissent pas de modifications significatives au cours de l'incubation.

Parmi les esters de cholestérol, l'oléate augmente progressivement du $\mathrm{ro}^{\mathrm{e}}$ au $20^{\mathrm{e}}$ jour, passant de $53,4 \mathrm{p}$. Ioo à 74 , I p. Ioo chez les témoins et de $30 \mathrm{p}$. Ioo à 43,4 p. Ioo chez les embryons du lot élaïdique. Dans ce lot, il faut remarquer la richesse en acide élaïdique des esters du cholestérol néoformés.

Enfin, quel que soit le lot, les phospholipides de l'embryon sont très différents de ceux du vitellus : ils sont plus riches en acide stéarique et en acide arachidonique, et plus pauvres en acide oléique. Les différences entre vitellus et embryon sont également très prononcées dans le cas des deux phosphoglycérides étudiés. Mais, alors que la composition des phosphatidyl-éthanolamines demeure relativement fixe entre le $\mathrm{IO}^{\mathrm{e}}$ et le $2 \mathrm{O}^{\mathrm{e}}$ jour d'incubation, celle des phosphatidyl-cholines change. 
Ces composés, comme les phospholipides totaux, s'enrichissent en acide stéarique. Enfin, entre les deux lots, il existe des différences marquées qui reflètent, mais de façon atténuée, celles du vitellus. Une seule exception, l'acide palmitique qui est réparti également entre les phospholipides de tous les embryons.

On remarque que dans tous les lipides de l'embryon l'acide élaïdique est présent en quantité notable; les esters du cholestérol étant les plus riches et les phospholipides les plus pauvres.

\section{TABI, EAU 7}

Composition en acides gras des phospholipides totaux du vitellus et de l'embryon $\dot{a}$ divers stades d'incubation

\begin{tabular}{|c|c|c|c|c|c|c|c|c|c|c|}
\hline Acides gras $\left({ }^{1}\right)$ & $16: 0$ & $\begin{array}{l}16: 1 \\
\text { cis }\end{array}$ & $18: 0$ & $\begin{array}{l}18: 1 \\
\text { cis }\end{array}$ & $\begin{array}{l}18: 1 \\
\text { trans }\end{array}$ & $\left|\begin{array}{c}18: 2 \\
\text { cis-trans }\end{array}\right|$ & $\begin{array}{l}18: 2 \\
\text { cis-cis }\end{array}$ & $18: 3$ & $\mathrm{Y}$ & $20: 4$ \\
\hline $\begin{array}{l}\text { Vitellus } \\
\text { non incubé }\end{array}$ & & & & & & & & & & \\
\hline Lot $\mathrm{T} \ldots \ldots \ldots$ & 27,8 & 4,2 & 17,7 & 38,6 & 0,0 & 0,0 & 6,9 & traces & 0,0 & 5,3 \\
\hline Lot $\mathrm{El} \ldots \ldots \ldots \ldots$ & 17,1 & 4,1 & 6,7 & 21,6 & 32,5 & 3,5 & 9,9 & 0,9 & 1,0 & 2,7 \\
\hline Vitellus résiduel & & & & & & & & & & \\
\hline Lot $\mathrm{T} \ldots \ldots \ldots$ & 29,0 & 3,2 & 18,6 & 37,8 & 0,0 & 0,0 & 6,2 & traces & 0,0 & 5,4 \\
\hline Lot $\mathrm{El}, \ldots \ldots \ldots$ & 17,0 & 3,7 & 7,2 & 22,2 & 31,8 & 3,5 & 9,6 & 1,0 & 0,8 & 3,0 \\
\hline $\begin{array}{l}\text { Embryon } \\
\text { de } 10 \text { jours }\end{array}$ & & & & & & & & & & \\
\hline Lot $T$ & $31,{ }_{k}^{\prime}$ & 3,8 & 17,3 & 27,6 & 0,0 & 0,0 & 4,0 & traces & - & 15,8 \\
\hline Lot El & 31,3 & 4,5 & 11,5 & 20,0 & 16,7 & 2,3 & 8,5 & traces & 一 & 5,2 \\
\hline $\begin{array}{l}\text { Embryon } \\
\text { de } 14 \text { jours }\end{array}$ & & & & & & & & & & \\
\hline Lot $T$. & 31,0 & 2,6 & 19,6 & 26,2 & 0,0 & 0,0 & 5,5 & traces & - & 15,0 \\
\hline Lot $\mathrm{El} \ldots \ldots \ldots$ & 28,5 & 3,7 & 12,1 & 18,0 & 15,7 & 2,8 & 10,1 & traces & - & 7,6 \\
\hline $\begin{array}{l}\text { Embryon } \\
\text { de } 20 \text { jours }\end{array}$ & & & & & & & & & & \\
\hline Lot $T$. & 31,2 & 1,5 & 23,1 & 25,1 & 0,0 & 0,0 & 5,6 & traces & - & 13,2 \\
\hline Lot $\mathrm{EI}$ & 27,9 & 2,6 & 14,6 & 16,9 & 17,7 & 1,5 & 10,4 & traces & - & 7,6 \\
\hline
\end{tabular}

(') Nous n'avons pas fait figurer ici des traces d'acides gras à nombre impair de carbones.

\section{DISCUSSION}

I a difficulté d'obtenir en quantité importante de la triélaïdine aussi pure que celle que nous avons utilisée, nous a obligé à limiter le nombre d'animaux et la durée de l'expérience. C'est pourquoi cette étude porte sur un nombre restreint de poules et partant sur un petit nombre d'embryons. Pour cette raison, il nous est 
impossible d'affirmer que l'isomère trans ne gêne pas l'embryogenèse. Il n'en demeure pas moins vrai que les lipides vitellins, pourtant très modifiés dans le lot élaïdique, permettent le développement d'embryons morphologiquement normaux.

\section{TABLEAU 8}

Composition en acides gras des phosphatidylcholines du vitellus et de l'embryon $\dot{a}$ divers stades d'incubation

\begin{tabular}{|c|c|c|c|c|c|c|c|c|c|c|}
\hline Acides gras (1) & $16: 0$ & $\begin{array}{l}16: 1 \\
\text { cis }\end{array}$ & $18: 0$ & $\begin{array}{c}18: 1 \\
\text { cis }\end{array}$ & $\begin{array}{l}18: 1 \\
\text { trans }\end{array}$ & $\begin{array}{c}18: 2 \\
\text { cis-trans }\end{array}$ & $\begin{array}{l}18: 2 \\
\text { cis-cis }\end{array}$ & $18: 3$ & $\mathrm{Y}$ & $20: 4$ \\
\hline $\begin{array}{l}\text { Vitellus } \\
\text { non incubé }\end{array}$ & & & & & & & & & & \\
\hline Lot $\mathrm{T} \ldots \ldots \ldots$ & 29,1 & 4,3 & 16,2 & 38,1 & 0,0 & 0,0 & 6,8 & traces & 0,0 & 4,5 \\
\hline Lot $\mathrm{El} \ldots \ldots \ldots$ & 18,0 & 3,8 & 6,6 & 25,0 & 29,8 & 3,4 & 9,8 & 1,0 & 1,0 & 2,1 \\
\hline \multicolumn{11}{|l|}{ Vitellus résiduel } \\
\hline Lot $\mathrm{T} \ldots \ldots \ldots$ & 27,3 & 4,2 & 18,5 & 38,6 & 0,0 & 0,0 & 6,6 & traces & 0,0 & 5,4 \\
\hline Lot El. & 17,6 & , 1 & 7,5 & 23,1 & 30,3 & 3,4 & 9,7 & 0,9 & 0,8 & 3,0 \\
\hline \multicolumn{11}{|l|}{$\begin{array}{l}\text { Embryon } \\
\text { de } 10 \text { jours }\end{array}$} \\
\hline Lot $T \ldots \ldots$ & 40,4 & 4,8 & 10,7 & 30,3 & 0,0 & 0,0 & 4,0 & traces & - & 9,7 \\
\hline Lot $\mathrm{El}$ & 35,3 & 4,6 & 7,9 & 18,0 & 17,0 & 3,0 & 9,3 & traces & - & 3,0 \\
\hline \multicolumn{11}{|l|}{$\begin{array}{l}\text { Embryon } \\
\text { de } 14 \text { jours }\end{array}$} \\
\hline Lot $T \ldots \ldots \ldots$ & 35,5 & 3,9 & 15,5 & 35,2 & 0,0 & 0,0 & 4,8 & traces & - & 5,1 \\
\hline Lot $\mathrm{El}$ & 33,3 & 4,3 & 11,2 & 18,0 & 15,1 & 2,7 & 11,3 & traces & - & 3,8 \\
\hline \multicolumn{11}{|l|}{$\begin{array}{l}\text { Embryon } \\
\text { de } 20 \text { jours }\end{array}$} \\
\hline Lot $T$ & 32,3 & 2,1 & 19,2 & $30, \mathbf{k}$ & 0,0 & 0,0 & 6,3 & traces & - & 9,1 \\
\hline Lot El & 30,8 & 3,1 & 10,1 & 20,2 & 17,1 & 1,9 & 11,3 & traces & 一 & 5,4 \\
\hline
\end{tabular}

(1) Nous n'avons pas fait figurer ici des traces d'acides gras à nombre impair de carbones.

Les résultats obtenus dans le lot témoin nous permettent de tirer quelques conclusions nouvelles concernant le métabolisme des lipides chez l'embryon. Nous discuterons d'abord ces résultats. Nous considérerons ensuite le lot élaïdique en essayant de montrer que 1'isomère trans est utilisé comme les autres acides gras, et que, de ce fait, il constitue un marqueur témoignant du devenir des lipides vitellins.

$$
\text { I L Lot Témoin }
$$

Tous les lipides du vitellus sont utilisés progressivement au cours de sa résorption : il n'y a pas d'absorption préférentielle d'un ou plusieurs acides gras au cours de l'incubation; ce qui rejoint les conclusions de Hir, Silbernick, Means (I965). 
Contrairement à l'opinion d'IsaAKs et al. (I964), il ne semble pas que les acides gras saturés soient moins facilement absorbés que les acides polydésaturés.

Les triglycérides des embryons de ce lot diffèrent peu de ceux de l'œuf. Ce résultat demeure valable au ro $^{\mathrm{e}}$ comme au $20^{\mathrm{e}}$ jour.

Il n'en est pas de même des esters du cholestérol. Les modifications que nous

TABLEAU 9

Composition en acides gras des phosphatidyl-éthanolamines du vitellus et de l'embryon $\dot{a}$ divers stades d'incubation

\begin{tabular}{|c|c|c|c|c|c|c|c|c|c|c|}
\hline Acides gras $(\mathbf{1})$ & $16: 0$ & $\begin{array}{l}16: 1 \\
\text { cis }\end{array}$ & $18: 0$ & $\begin{array}{l}18: 1 \\
\text { cis }\end{array}$ & $\begin{array}{l}18: 1 \\
\text { trans }\end{array}$ & $\left|\begin{array}{c}18: 2 \\
\text { cis-trans }\end{array}\right|$ & $\begin{array}{l}18: 2 \\
c i s-c i s\end{array}$ & $18: 3$ & $\mathrm{Y}$ & $20: 4$ \\
\hline \multicolumn{11}{|l|}{$\begin{array}{l}\text { Vitellus } \\
\text { non incubé }\end{array}$} \\
\hline Lot $\mathrm{T}$. & 20,9 & 1,9 & 28,3 & 30,0 & 0,0 & 0,0 & 6,2 & traces & 0,0 & 12,5 \\
\hline Lot El ... & 12,5 & 2,0 & 10,0 & 23,1 & 32,6 & 2,8 & 9,2 & 0,9 & 0,9 & 6,3 \\
\hline \multicolumn{11}{|l|}{$\begin{array}{l}\text { Vitellus } \\
\text { résiduel }\end{array}$} \\
\hline Lot $\mathrm{T}$ & 19,4 & 1,9 & 27,9 & 29,9 & 0,0 & 0,0 & 6,4 & traces & 0,0 & 13,7 \\
\hline Lot $\mathrm{EI}$ & 13,5 & 2,8 & $10, y^{\prime}$ & 20,2 & 32,1 & 3,5 & 10,1 & 0,9 & 0,8 & 6,8 \\
\hline \multicolumn{11}{|l|}{$\begin{array}{l}\text { Embryon } \\
\text { de } 10 \text { jours }\end{array}$} \\
\hline Lot $T$. & 15,0 & 1,7 & 29,5 & 20,6 & 0,0 & 0,0 & 2,8 & traces & - & 30,6 \\
\hline Lot El & 21,1 & 3,2 & $17, y^{\prime}$ & 18,2 & 16,1 & 2,7 & 8,8 & traces & - & 13,0 \\
\hline \multicolumn{11}{|l|}{$\begin{array}{l}\text { Embryon } \\
\text { de } 11^{\prime} \text { jours }\end{array}$} \\
\hline Lot $T \ldots \ldots \ldots$ & 16,1 & 1,8 & 27,0 & 26,1 & 0,0 & 0,0 & 5,0 & traces & - & 23,6 \\
\hline Lot El & 17,2 & 2,8 & $19, y^{\prime}$ & 18,2 & 16,1 & 2,1 & 10,7 & traces & 一 & 13,2 \\
\hline \multicolumn{11}{|l|}{$\begin{array}{l}\text { Embryon } \\
\text { de } 20 \text { jours }\end{array}$} \\
\hline Lot $\mathrm{T} \ldots \ldots \ldots$ & 15,8 & 1,3 & 30,7 & 21,6 & 0,0 & 0,0 & 5,6 & traces & - & 24,6 \\
\hline Lot $E 1 \ldots$ & 14,7 & 2,1 & 19,1 & 18,1 & 18,1 & 1,6 & 10,2 & traces & 一 & 16,2 \\
\hline
\end{tabular}

(1) Nous n'avons pas fait figurer ici des traces d'acide gras à nombre impair de carbones.

avons rapportées rejoignent celles d'autres auteurs (NOBLE et MOORE, Ig65 ; FELDMAN et GRANTHAM, I964). La proportion d'oléate s'élève considérablement en fin d'incubation. Inversement 1'arachidonate diminue et n'est plus décelable à cette époque. Parallèlement le taux d'estérification du cholestérol augmente (TsuJI, I955) et le poussin éclôt avec un foie gras dont plus de 70 p. Ioo des lipides sont formés par les esters du cholestérol (FELDMAN et Grantham, I964). Ce phénomène semble très général, puisqu'on le constate également chez le jeune mammifère à la naissance (DEUEI, I955). D'autres recherches devraient permettre de relier ces phénomènes afin de préciser cet aspect particulier du métabolisme du cholestérol au moment du passage à la vie aérienne. 
Les phospholipides de l'embryon, quel que soit son stade de développement, ont une composition en acides gras très différente de ceux de l'œuf. C'est ainsi qu'il y a davantage d'acide stéarique et d'acide arachidonique et moins d'acide oléique dans les phosphatidyl-cholines et les phosphatidyl-éthanolamines, qui à eux seuls représentent toujours plus de $70 \mathrm{p}$. Ioo des phospholipides totaux. Au cours de l'incubation on remarque que le taux d'acide stéarique s'élève dans les phospholipides totaux. Ce fait a déjà été observé dans le foie (FELDman et Grantham, I964) et dans l'embryon entier (SÉzILLE et BISERTE, I964). Contrairement à l'opinion de ces derniers les phosphatidyl-éthanolamines ne sont pas responsables de ce phénomène ; en effet, la proportion de ces phosphoglycérides, très riches en acide stéarique,

\section{TABLEAU IO}

Composition en acides gras des esters de cholestérol de l'embryon $\dot{a}$ divers stades d'incubation

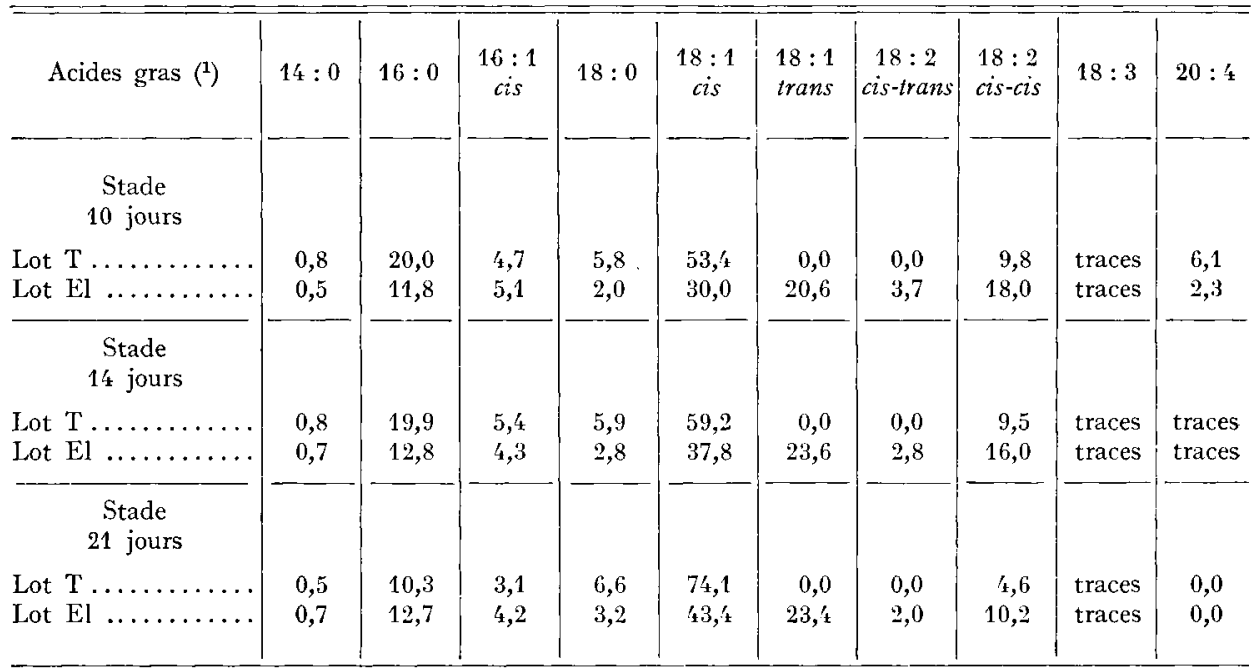

(1) Nous n'avons pas fait figurer ici des traces d'acides gras à nombre impair de carbones.

décroît au cours du développement embryonnaire (BIEBER et CHELDELIN, I962) et leur composition reste à peu près fixe, d'après nos résultats. Par contre, les phosphatidyl-cholines s'enrichissent en acide stéarique. C'est à cet enrichissement et peut-être à une augmentation des sphingomyélines (BIEBER et CHELDELIN, I962) qu'il faut rapporter l'accroissement du taux d'acide stéarique dans les phospholipides totaux.

\section{2. - Lot Élaïdique}

Toutes les observations que nous venons de commenter dans le cas du lot témoin auraient pu être faites en analysant les résultats du lot élaïdique ; cela malgré des compositions en acides gras du vitellus et de l'embryon très différentes dans les deux lots. Dans leurs caractéristiques générales, l'utilisation et le métabolisme des 
lipides ne semblent pas modifiés par l'acide élaïdique : de même, nous l'avons vu le développement embryonnaire ne parait guère perturbé.

Chez la Poule (LECLERCQ, I965) comme chez le Rat (LORIETTE, I965) l'acide élaïdique s'incorpore dans les lipides, en se substituant aux acides saturés et pour une moindre part à l'acide oléique. Comme chaque acide gras, il présente des caractères qui lui sont propres, mais également les propriétés métaboliques générales de la plupart des acides gras naturels. En particulier, il peut être brûlé à des fins énergétiques (Coots, I964) ou désaturé par l'animal (LEMARCHAL, I966). Il en est vraisemblablement de même chez l'embryon de poulet. On peut donc considérer l'acide élaïdique comme un marqueur permettant de suivre, au cours de l'embryogenèse, la destinée des acides gras et tout particulièrement de ceux qu'il a remplacés dans les lipides vitellins.

On sait déjà que les acides gras essentiels des lipides de l'embryon proviennent du vitellus, puisqu'ils ne peuvent pas être synthétisés. Pour les autres acides gras édifiables aux dépens de molécules plus simples (HALEVy et GEYER, I96I), on peut se demander quelle est la part qui revient à ces synthèses et celle qui correspond à un transfert direct à partir du vitellus. Les essais réalisés jusqu'à présent à 1'aide d'éléments radio-actifs ne permettent pas de répondre à cette question. En particulier, Budowski et al., ( 1962 ) ont nourri des poules avec une tripalmitine marquác à la fois sur le glycérol et sur l'acide gras. Ils ont comparé les activités spécifiques din glycérol et des acides gras dans l'œuf et dans l'embryon. Mais leur étude ne porte que sur les acides gras totaux sans discerner la répartition de l'isotope entre ces divers acides. Il n'est donc pas possible à partir de ces résultats de distinguer ce qui correspond à des transferts sans remaniements ou à des synthèses $d e$ novo. Nous pensons apporter à ce sujet quelques éclaircissements.

De ce point de vue, on doit distinguer les phospholipides des triglycérides. Dans ces derniers la proportion de 1'isomère trans (22,2 p. I00) a peu diminué par rapport à ce qu'elle était dans les triglycérides du vitellus (30, I p. I00). On remarque également une étroite ressemblance dans leur composition en acides gras. En particulier, les taux d'acide linoléique de l'embryon et du vitellus sont très voisins et très liés (corrélation de 0,95 pour $\mathrm{I} 2$ données). L'hypothèse d'une incorporation sans remaniements d'une partie importante de ces constituants vitellins dans l'embryon est tout à fait vraisemblable. Budowski et al. (Ig62) aboutissent aux mêmes conclusions.

Dans les phospholipides de l'embryon la proportion d'acide élaïdique (I 7,7 p. roo) est nettement plus faible que dans les phospholipides de l'œuf où elle atteint 32,5 p. I00. On trouve aussi des différences importantes dans le cas des autres acides gras. Il semble donc qu'une bonne partie des phospholipides soit synthétisée de novo par l'embryon ou en tout cas que les phospholipides d'origine vitelline soient profondément remaniés. Nos résultats concordent avec ceux obtenus par BuDowski et al. (I962). Apparemment ils s'opposent à cet1x de Srek et NEwburgh (I965). En effet, après injection dans l'œuf en incubation de phosphatidyl-cholines et de phosphatidyl-éthanolamines marqués avec du $\mathrm{P}^{32}$, ces auteurs ont conclu qu'une partie des phospholipides vitellins est retrouvée intacte dans l'embryon. Pour concilier ces données avec celles de BUDowski et les nôtres, on peut imaginer que l'embryon utilise une partie importante des phospholipides vitellins sans hydrolyse des liaisons de l'acide phosphorique avec la base azotée ; mais les acides gras et le glycérol sont 
certainement différents de ceux de la molécule d'origine vitelline. Une telle hétérogénéité de renouvellement des divers composants des molécules de phosphoglycérides a déjà été mise en évidence dans la cellule hépatique (PASCAUD, I964).

En résumé, l'embryon est capable de synthétiser de nouveaux acides gras, mais il utilise également sans les remanier une bonne partie de ceux qui se trouvent dans le vitellus. Dans le lot élaïdique la proportion des acides gras dans les lipides de l'œuf est profondément modifiée. Ces modifications se retrouvent, quoique atténuées, chez l'embryon : appauvrissement en acides stéarique et oléique, diminution du taux d'acide arachidonique dont on sait que la biosynthèse est inhibée par l'acide élaïdique (RAulis et al., I965). Une exception cependant concerne l'acide palmitique. La part des synthèses apparaît prépondérante puisque les phospholipides de l'embryon sont également pourvus de cet acide dans les lots témoin et élaïdique, malgré un apport vitellin très différent.

\title{
CONCLUSION
}

Contrairement à ce qui se passe chez les mammifères (Johns'Ton, Johnston et Kummerov, I957), on retrouve des quantités importantes d'acide élaïdique dans l'embryon d'oiseau lorsque sa mère a ingéré une matière grasse élaïdisée. Or on sait que l'embryon d'oiseau ne dispose que de traces de glucides libres et d'une quantité énorme de lipides dont le tiers est formé par des phospholipides. Ces lipides sont absorbés par le sac vitellin sans être notablement hydrolysés. Au contraire, l'embryon de mammifère dispose tout au long de son développement de quantités importantes de sucres libres. De plus, le placenta joue un rôle de barrière sélective et ne laisse passer que les acides gras libres ; qui, d'ailleurs, diffusent en faibles quantités (KOREN et SHAFFir, I964). Ces particularités font que pour ce qui est de ses lipides, l'embryon d'oiseau apparaît beaucoup plus dépendant du régime maternel que l'embryon de mammifère (FAIN et Scow, I966).

Reçu pour publication en juin 1966.

\section{REMERCIEMENTS}

Nous remercions la Société ASTRA-CALVÉ qui nous a fourni la triélaïdine

\section{SUMMARY}

\begin{abstract}
METABOLISM OF LIPIDS IN THE CHICK EMBRYO : UTILIZATION OF VITELLINE RESERVES
\end{abstract} IN THE PRESENCE OF ELAIDIC ACID SUPPLIED TO THE EGG BY THE LAYING BEN

Two groups of hens were fed, one on a control diet poor in crude fat and the other on a diet supplying the same energy and protein, derived from the control diet by replacing cerelose with a mixture of cellulose and trielaidin; the diet had 8 p. Ioo trielaidin. 
Compared with controls the hens given trielaidin showed the following characteristics :

The vitellus of the egg had about 30 p. roo elaidic acid.

The embryos from those eggs seemed to be viable; there was no abnormality during development.

Large amounts of elaidic acid were found in the embryo. The proportion of this fatty acid was greater in the cholesterol esters $(23,4 \mathrm{p}$. I00) and the triglycerides $(22.2 \mathrm{p}$. I00) than in the phospholipids ( 77.7 p. I00).

The modifications in fatty acid composition of the vitellus were repeated in the embryo, but to a smaller degree.

As far as it is permissible to consider elaidic acid as a marker it can be seen that the embryo incorporates in its tissues a large part of the fatty acids from the vitellus. For the triglycerides the phenomenon can be due mainly to the incorporation of complete molecules from the vitellus by the embryo. Such an explanation cannot be applied to the phospholipids, of which the modifications are very much greater. The chick embryo is thus shown to be more dependent on the maternal diet than is the mammalian.

\section{RÉFÉRENCES BIBLIOGRAPHIQUES}

Bieber A. L., Cimeldelix V. H., Newburg R. W., ig62. Ihospholipid patterns of developping chick embryo. Biochemistry, 1, 532-536.

Budowski P., Bottino N. R., Reiser R., ig6r. Lipid transport in the laying hen and the incubating egg. Archs. Biochem. Biophy's., 93, 483-490.

Calet C., I959. Données nouvelles sur l'influence de l'alimentation sur la quantité et la composition des lipides de l'ouf. Ann. Nulrit. Aliment., 13, A $163-\mathrm{A} 203$.

Coots R. H., I964. A comparison of the metabolism of elaidic, oleic, palmitic and stearic acids in the rat. J. Lifid Res., 5, $468-472$.

Deuel H. J., 1955. The Lipids, vol. II. Interscience Publishers, New York, pp. 919.

FAIN J. N., Scow R. O., ig66. Fatty acid synthesis in matemal and fotal tissues. Am. J. Physiol., 210, $19-25$.

Feldman G. L., Grantiam C. K., ig64. Lipids in embryonic liver. Poullry Sci., 43, I51-i53.

Halevy S., Geyer R. P', i96r. Comparison of lipid motabolism of chicken embryo organs and cells in culture. Proc. Soc exper. Biol. Med., 108, 6-9.

Hill E. G., Silbernick C. L., Mc Means I., I965. Polyunsatured fatty acids in incubating chicken egg lipids. Poultry Sci., 44, 894-896.

Isaaks R. E., Davies R. Ji., Ferguson T. M., Reiser R., Colch J. R., 1964. Studies on avian fat composition. 2. The selective utilization of fatty acids by the chick embryo. Poullyy Sci., 43, I 1 3-120.

Jonnston P. V., Johnston O. C., Kummerov F. A., 1957. Non transfert of trans fatty acids from mother to young. Proc. Soc. exp. Biol. Med., 96, $760-762$.

Koren Z., Shaffir E., I964. Placental transfert of free fatty acids in the pregnant rat. Proc. Soc. exper. Biol. Med., 116, 4I I-4I4.

Leclerce B., Brum J. C., JaCovot R., 1965. Etude de l'utilisation de l'acide élaïdique au cours de l'ovogenése de Gallus gallus : son incorporation dans les graisses de réserves et dans les lipides du vitellus de l'ouf pondu. C. R. Acad. Sci., 261, 3 I97-3200.

Leclerce B., Agot A., Lemarchal P., I966. Microdosage des acides gras monoéthyléniques de forme trans en présence de leur isomère cis, par l'emploi simultané de la chromatographie en couche nince et de la chromatographie gaz-liquide. Bull. Soc. Chim. biol., 48, 345-352.

Lemarchal P., I966. Déshydrogénation de l'acide élaïdique in vitro par des homogénats de foie de Rat. C. R. Acad. Sci., 262, 816-819.

Loriette C., Clénent G., RnUlin J., ig62. Influence de l'ingestion prolongée d'huile d'arachide renfermant des acides gras polydésaturés trans sur la structure des triglycérides de réserve chez le Rat blanc C. R. Acad. Sci., 255, $2204-2206$.

Needham J., 1931. Chemical embryology, vol. 2, Cambridge Liniversity Press, London.

Neudoerffer T. S., Lea C. H., I966. Antioxydants for the thin layer chromatography of lipids. J. Chromat., 21, $138-140$.

Noble R. C., Moore J. H., 1965. Further studies on the lipid metabolism of the normal and vitamin $\mathrm{B}_{12}$ - deficient chick embryo. Biochem. J., 95, 144-149.

Pascaud M., i964. Les phospholipides de la cellule hépatique. Interprétation fonctionnelle de leur renouvellement. 2. Renouvellement des acides gras des phosphoglycérides. Biochim. biophys. Acta, 84, 528-534.

Raulin J., Lapous D., Dauvillier P., Rérat A., I965. Incorporation préférentielle des acides gras élaïdisés en position $\alpha$ des phospholipides hépathiques du porc. C. R. Acad. Sci, 260, 344-347. 
Sézille C.,Biserte G., I 964 . Évolution des lipides de l'œuf de poule au cours du développement embryonnaire. C. R. Soc. Biol., 158 i 623 -1626.

Siek T. J., Newburgh R. W., I965. Origin of phospholipids in the chick embryo during development. J. Lipid Res., 6, 556-564.

Skipski V. P., Peterson R. F., Sanders J., Barclay M., i963. Thin layer chromatography of phospholipids using silicagel without sulfate binder. J. Lipid Res., 4, 227.

TsuyI F. I., BRIN M., Williams II. H., I955. Lipid phosphorus and cholesterol changes in hen's egg during incubation. Archs. Biochem. Biophys., 56, 290-296. 